\title{
Postural Stability and Responses to Vibrations in Patients After Anterior Cruciate Ligament Surgical Reconstruction
}

\author{
Z. HIRJAKOVÁ ${ }^{1 *}$, H. ŠINGLIAROVÁ ${ }^{2,3^{*}}$, D. BZDÚŠKOVÁ ${ }^{1}, J_{.}$KIMIJANOVÁ ${ }^{1}$, \\ K. BUČKOVÁ ${ }^{1}$, P. VALKOVIČ ${ }^{1,2}$, F. HLAVAČKA ${ }^{1}$ \\ * These authors contributed equally to this work.
}

${ }^{1}$ Laboratory of Motor Control, Institute of Normal and Pathological Physiology, Slovak Academy of Sciences, Bratislava, Slovakia, ${ }^{2}$ Second Department of Neurology, Faculty of Medicine, Comenius University, Bratislava, Slovakia, ${ }^{3}$ Department of Rehabilitation, University Hospital, Bratislava, Slovakia

Received June 21, 2016

Accepted September 5, 2016

\section{Summary}

The aim of the study was to evaluate the effect of surgical reconstruction of anterior cruciate ligament $(\mathrm{ACL})$ on postural stability and responses to lower limb (LL) muscles vibrations. Centre of pressure (CoP) was measured in 17 subjects during stance on firm/foam surface with eyes open/closed and during unilateral vibrations of LL muscles ( $m$. triceps surae - TS, $m$. quadriceps femoris - $\mathrm{Q}, m$. quadriceps femoris and hamstrings simultaneously - $\mathrm{QH})$. The measurements were performed: 1) preoperatively, 2) six weeks and 3) three months after the reconstruction. Decreased postural stability was documented six weeks after the reconstruction compared to preoperative measurement. Three months after the reconstruction significant improvement was observed during stance on foam surface with eyes closed. Preoperatively, altered reactions of $\mathrm{LL}$ with $\mathrm{ACL}$ lesion compared to intact $\mathrm{LL}$ were manifested by slower response in first $3 \mathrm{~s}$ of TS vibration and by increased CoP shift in last $5 \mathrm{~s}$ of $\mathrm{QH}$ vibration. After the reconstruction, we observed slower CoP reaction and decreased CoP shift during TS vibration of LL with ACL lesion compared to preoperative level. Posturography during quiet stance and during TS vibration reliably detect postural changes due to $\mathrm{ACL}$ reconstruction and can be potentially useful in clinical practice.

\section{Key words}

Anterior cruciate ligament lesion • Ankle joint • Knee joint • Posture • Vibration

\section{Corresponding author}

Z. Hirjaková, Institute of Normal and Pathological Physiology, Slovak Academy of Sciences, Sienkiewiczova 1, 81371 Bratislava, Slovakia. E-mail: zuzana.hirjakova@savba.sk

\section{Introduction}

Lesion of anterior cruciate ligament (ACL) is the most studied ligamentous knee trauma leading to deficiency of proprioception and stability, reduction of muscle strength and functional performance. Ligamentous trauma of weight-bearing joints is not only biomechanical problem in terms of joint instability (Kapreli and Athanasopoulos 2009, Kvist 2008, Kvist 2006, Wikstrom et al. 2006), but presents also deafferentation trauma (Bonfim et al. 2003). Decreased proprioception and increased nociception modulate afferent flow, cause disturbance in the neuromuscular control and affect the motor responses, resulting in dysfunction of the injured limb (Kapreli and Athanasopoulos 2006). Proprioception altered by trauma leads to regulatory dysfunction, delayed muscle reaction and reduced quality of movement coordination, predisposing patient to further trauma and orthopedic disorders arising from overloading (Kolář 2009). Reconstruction of ACL by replacing hamstring graft or patellar ligament restores mechanical stability, but functional deficit remains after the operation, which is the reason why nearly half of the athletes will not return to 
the previous level of sports activity (Ardern et al. 2014). Proprioception is discussed topic including different views and results, with restoration occurring from six months (Gholam et al. 2013, Reider et al. 2003) to 12-18 months after the surgery (Angoules et al. 2011).

Close link between sensory and motor functions are known for a long time. Proper somatosensory afferent information is necessary for good posture and targeted movements. Proprioceptive inputs from lower limbs (LL) are generally considered important in the balance control. They inform about quality and characteristics of the support surface and about the position of body segments. They also provide a feedback about on-going moves and detect a disruption of balance (Smiley-Oyen et al. 2007). Vibration of leg muscles (mostly Achilles tendon or m. triceps surae) is one of the commonly used methods for externally induced balance perturbations in healthy individuals (Shanahan et al. 2014, Duclos et al. 2014, Abrahámová et al. 2009, Čapičíková et al. 2006), but less often in patients with knee disorders (Shanahan et al. 2014). Muscle or tendon vibration generates proprioceptive information which is not congruent with actual body position and alters spatial body orientation. It evokes kinesthetic illusion of body movement in standing object and postural response to the vibration is known as vibratory-induced falling (Eklund 1973). Vibratory stimulation of the quadriceps muscle in the leg that has undergone ACL reconstruction was also used for a treatment to enhance body stability (Brunetti et al. 2006). Short-lasting vibratory treatment improved the single-limb standing balance and the extensor muscle torque of the operated leg. In our study, the vibrations of LL muscles were used to detect the ability of the patient after ACL surgical reconstruction to compensate the disturbing input to ankle and knee joint muscles.

The aim of the study was to obtain new knowledge about postural stability and postural responses to LL muscles vibration of patients with anterior cruciate ligament lesion before and after the surgical reconstruction and rehabilitation focused on proprioceptive improvement. We hypothesize the presence of decreased postural stability six weeks and also 3 months after the ACL reconstruction in quiet standing. We also presume that vibrations of knee joint and ankle joint muscles of the LL with ACL lesion will induce altered postural reactions before and after the ACL reconstruction due to impaired proprioception.

\section{Methods}

Seventeen subjects (15 men, 2 women; mean age $30.5 \pm 8.7$ years; mean BMI 25.5 \pm 3.5$)$ with ACL lesion verified by the magnetic resonance imaging (MRI), participated in the study. The average period from the injury to surgery was 27.7 months. The reconstruction of ACL was made by bone-tendon-bone (BTB) graft from patellar ligament. Exclusion criteria were: dislocation of knee joint, lesion of posterior cruciate ligament or collateral ligaments, and history of lower limb surgeries, neurological, vestibular or vascular dysfunctions. Eight patients $(47 \%)$ underwent simultaneous surgical treatment of meniscus on LL with ACL. The study was approved by the Local Ethics Committee. Written consent in agreement with the Declaration of Helsinki was obtained from all participants.

Posturography was used for evaluation of postural stability and responses to vibrations of LL muscles 1) preoperatively, 2) six weeks and 3) three months after the surgery and rehabilitation. Early rehabilitation program (3-6 weeks after the reconstruction) was realized three times per week for $30 \mathrm{~min}$ with the focus on restoration of gait stereotype, knee joint function and proprioception, using elements of neurocognitive rehabilitation. Late rehabilitation program (6-12 weeks after the reconstruction) was realized twice per week for $30 \mathrm{~min}$ with the focus on restoration of proprioception, neuromuscular regulation, coordination and muscle strength.

The balance control was measured during quiet stance in four conditions: stance on a firm support surface with eyes open (EO) and closed (EC) and stance on a foam surface (thickness $10 \mathrm{~cm}$ ) with eyes open (FEO) and closed (FEC) (Lobotková et al. 2013, Abrahámová and Hlavačka 2008). Subjects stood on a force platform, barefoot, feet shoulder-width apart, straight-ahead position, arms by the sides of the body. They were instructed to stand quietly and to breathe normally. Each trial lasted for $50 \mathrm{~s}$. Centre of pressure $(\mathrm{CoP})$ displacement in both directions, anteriorposterior (AP) and medial-lateral (ML), was measured by the custom made force platform with three force transducers inbuilt, equipped with automatic weight correction for different output of CoP. Output signals were sampled by frequency of $100 \mathrm{~Hz}$ and recorded online on PC. Five CoP parameters were evaluated using the software MATLAB (MATLAB, Mathworks, Inc., Natick, MA, USA): amplitude in anterior-posterior (Aap) and medial-lateral (Aml) direction, mean velocity in anterior- 
posterior (Vap) and medial-lateral (Vml) direction and line integral (LI), which represents the length of the curve of statokinesigram. Data were statistically analyzed with the software SPSS (SPSS Inc., Chicago, IL, USA). One-way ANOVA was used for statistical analysis of $\mathrm{CoP}$ parameters in each condition (EO, EC, FEO, FEC) separately. Main factor was: Session (preoperative / after 6 weeks / after 3 months). Post-hoc pairwise comparisons with Bonferroni adjustments were performed for further exploration of differences between these three sessions. The level of significance was set at $\mathrm{p}<0.05$.

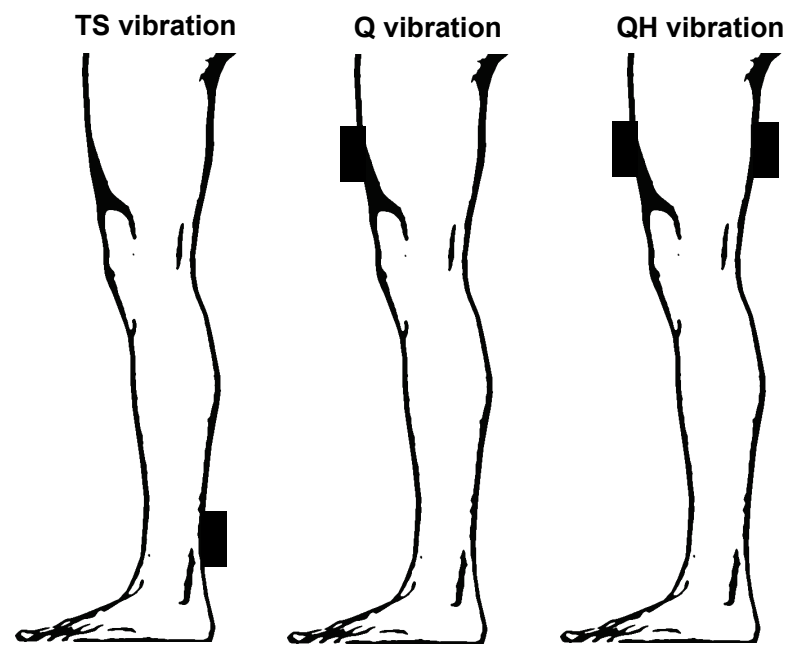

Fig. 1. Location of vibrators for unilateral vibration applied to the $m$. triceps surae (TS vibration), $m$. quadriceps femoris ( $Q$ vibration) and simultaneous vibration of $m$. quadriceps femoris and hamstrings ( $\mathrm{QH}$ vibration).

Vibrations of LL muscles: $m$. triceps surae (TS vibration), m. quadriceps femoris (Q vibration) and simultaneous vibration of $m$. quadriceps femoris and hamstrings ( $\mathrm{QH}$ vibration) were realized on each LL separately (Fig. 1), measured three times and then averaged. Each condition lasted $30 \mathrm{~s}$ (10 s of quiet standing, $10 \mathrm{~s}$ of vibration, $10 \mathrm{~s}$ of quiet standing). Subject was instructed to stand quietly with eyes open. The frequency of the vibration was $60 \mathrm{~Hz}$ with the amplitude of $1 \mathrm{~mm}$. In pilot measurements, frequencies higher than $60 \mathrm{~Hz}$ were destabilizing and induced postural strategies with stepping and reaching (Horak 2006), therefore we used frequency of $60 \mathrm{~Hz}$ (Abrahámová et al. 2009). The vibrator was DC motor with eccentric rotational load of $5 \mathrm{~g}$, encased in the plastic tube with the high of $9 \mathrm{~cm}$ and diameter of $5 \mathrm{~cm}$. Reaction to vibrations was quantified by the shift and slope of CoP displacement in AP direction. The CoP shift (last $5 \mathrm{~s}$ of postural reaction to muscle vibration) represents postural orientation induced by the vibration compared to CoP position prior to the vibration. CoP slope (first $3 \mathrm{~s}$ of postural reaction to muscle vibration) represents the speed of the reaction to the vibration in AP direction. Repeated measures ANOVA were used for statistical analysis with main factors: ACL lesion (intact LL / LL with ACL lesion) and Session (preoperative / after 6 weeks / after 3 months). Post-hoc multiple pairwise comparisons with Bonferroni adjustments were performed for further exploration of differences between sessions for each LL separately. Student's $t$-test was used for exploration of responses of lower limbs to the vibrations. The level of significance was set at $\mathrm{p}<0.05$.

\section{Results}

In four static conditions, decreased postural stability occurred six weeks after ACL reconstruction compared to preoperative measurement. Posturography showed increased CoP parameters values mostly during the stance on firm support surface. ANOVA proved statistically significant effect of the factor Session in parameters: $A m l \quad(F=3.802, \quad d f=2, \quad p=0.033), \quad$ Vap $(\mathrm{F}=7.095, \mathrm{df}=2, \mathrm{p}=0.003)$ and LI $(\mathrm{F}=7.019, \mathrm{df}=2$, $\mathrm{p}=0.003$ ) in $\mathrm{EO}$ condition and in parameter Vap in EC condition $(\mathrm{F}=4.051, \mathrm{df}=2, \mathrm{p}=0.027)$. Post-hoc multiple comparisons with Bonferroni adjustment proved significant differences $(p<0.05)$ between preoperative session and the session 6 weeks after reconstruction in these parameters (Fig. 2A).

Three months after the reconstruction, we observed significant improvement of postural stability compared to the measurement 6 weeks after the reconstruction. Decrease of $\mathrm{CoP}$ parameters was evident during the most challenging postural condition: stance on unstable foam surface with eyes closed (FEC). ANOVA showed significant effect of the main factor Session in parameters: Aml ( $\mathrm{F}=3.363, \mathrm{df}=2, \mathrm{p}=0.047), \mathrm{LI}(\mathrm{F}=3.327$, $\mathrm{df}=2, \mathrm{p}=0.049)$ and $\mathrm{Vml}(\mathrm{F}=4.535, \mathrm{df}=2, \mathrm{p}=0.018)$ in FEC condition. Post-hoc comparisons proved significant differences $(\mathrm{p}<0.05)$ between the sessions realized 6 weeks and 3 months after the reconstruction in these parameters (Fig. 2B).

Before the surgical reconstruction, different responses of lower limbs to TS vibration were documented. ANOVA showed significant effect of the factor ACL lesion in the CoP slope during TS vibration $(\mathrm{F}=4.702, \mathrm{df}=1, \mathrm{p}=0.046)$. Post-hoc $t$-test revealed slower $\mathrm{CoP}$ reaction during the vibration of $\mathrm{LL}$ with $\mathrm{ACL}$ lesion 
compared to the vibration of intact LL ( $p=0.003$ ). Different responses of legs to TS vibration were no longer observed after the ACL reconstruction (Table 1, Fig. 3).

Six weeks and three months after the surgical reconstruction, decreased sensitivity to TS vibration was documented in the LL with ACL lesion compared to preoperative measurement. ANOVA proved significant effect of the factor Session $(\mathrm{F}=3.811, \mathrm{df}=2, \mathrm{p}=0.034)$ in CoP shift. Post-hoc multiple comparisons revealed significantly reduced CoP shift six weeks $(p=0.039)$ and three months $(p=0.047)$ after the surgery compared to preoperative session in response to TS vibration of LL with ACL lesion (Table 1, Fig. 3).

Significant effect of the factor Session $(\mathrm{F}=6.042$, $\mathrm{df}=2, \mathrm{p}=0.006$ ) was proved by ANOVA also in CoP slope during TS vibration. Three months after the surgery, slower CoP reaction to TS vibration of LL with ACL lesion was observed compared to preoperative level $(p=0.003)$ (Table 1, Fig. 3).
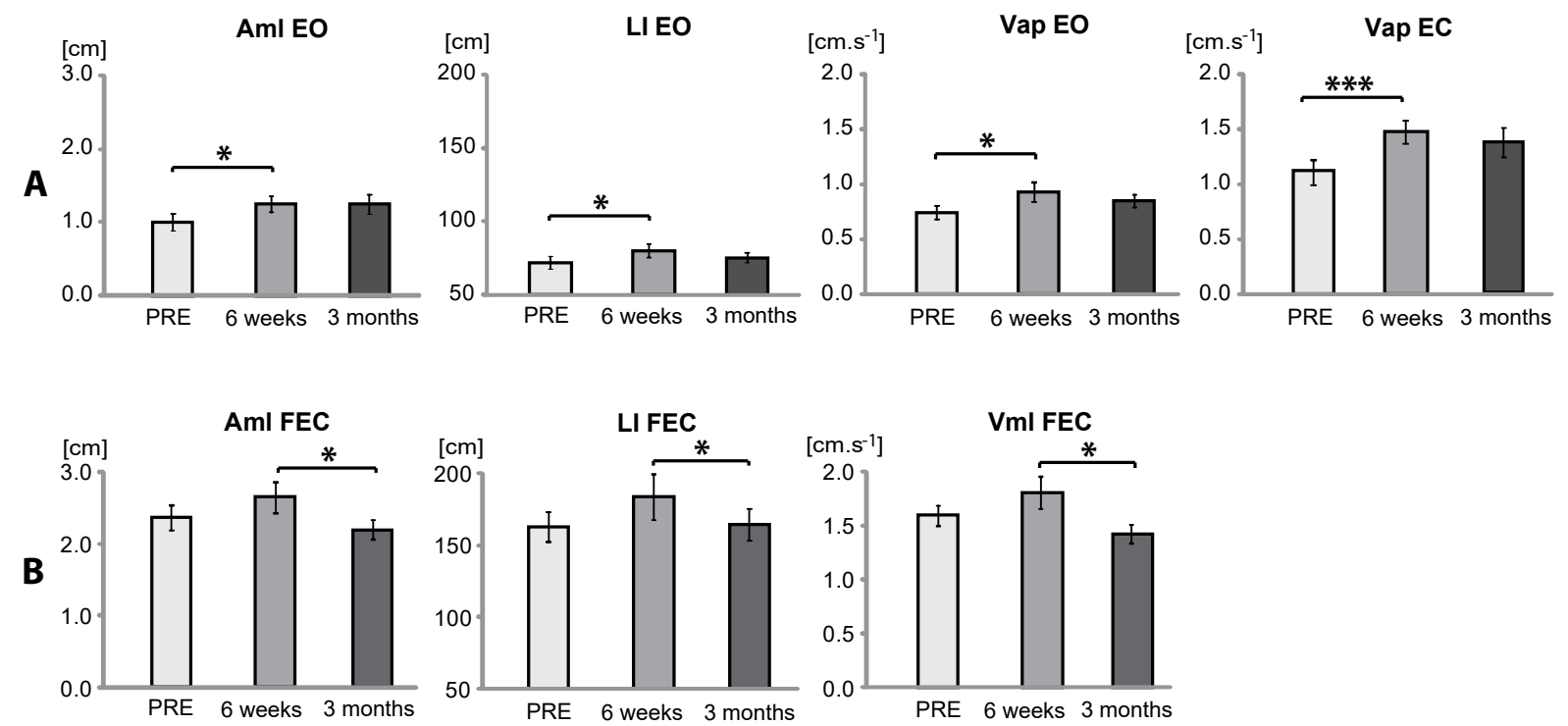

Fig. 2. The mean values of CoP parameters (Aml, LI, Vap, Vml) during stance on $\mathbf{A}$ ) firm surface with eyes open (EO) and closed (EC) and during stance on B) foam surface with eyes closed (FEC) measured preoperatively (PRE), 6 weeks and 3 months after ACL reconstruction. Data are presented as mean $\pm \mathrm{SEM} ;{ }^{*} \mathrm{p}<0.05, * * * \mathrm{p}<0.001$.

Table 1. The mean values of parameters: CoP shift and COP slope induced by TS vibration and QH vibration before ACL reconstruction (PRE), 6 weeks and 3 months after ACL reconstruction.

\section{TS vibration}

\begin{tabular}{llll}
\hline CoP shift $(\mathbf{c m} \pm$ SEM) & PRE & 6 weeks & 3 months \\
\hline LL with ACL lesion & $-1.23( \pm 0.13)$ & $-0.92( \pm 0.11)^{*}$ & $-0.96( \pm 0.14)^{*}$ \\
Intact LL & $-1.28( \pm 0.11)$ & $-1.09( \pm 0.14)$ & $-1.00( \pm 0.18)$ \\
CoP slope (cm.s ${ }^{-1} \pm$ SEM) & PRE & 6 weeks & $\mathbf{3 ~ m o n t h s ~}$ \\
\hline LL with ACL lesion & $-1.00( \pm 0.13) \dagger \dagger$ & $-0.78( \pm 0.11)$ & $-0.52( \pm 0.15)^{* *}$ \\
Intact LL & $-1.49( \pm 0.17)$ & $-1.04( \pm 0.21)$ & $-1.03( \pm 0.28)$ \\
\hline
\end{tabular}

\begin{tabular}{llll}
\hline \multicolumn{3}{c}{ QH vibration } & \\
\hline CoP shift (cm \pm SEM) & PRE & 6 weeks & 3 months \\
\hline LL with ACL lesion & $0.94( \pm 0.16) \dagger$ & $0.99( \pm 0.24)$ & $1.03( \pm 0.28)$ \\
Intact LL & $0.69( \pm 0.14)$ & $0.84( \pm 0.29)$ & $1.00( \pm 0.31)$ \\
CoP slope (cm.s ${ }^{-1} \pm$ SEM) & PRE & 6 weeks & 3 months \\
\hline LL with ACL lesion & $0.85( \pm 0.23)$ & $0.84( \pm 0.16)$ & $1.02( \pm 0.20)$ \\
Intact LL & $0.80( \pm 0.20)$ & $0.96( \pm 0.19)$ & $0.91( \pm 0.27)$ \\
\hline
\end{tabular}

Marked condition vs. PRE: ${ }^{*} p<0.05, * * p<0.01$; marked condition vs. Intact LL: $\dagger p<0.05,+\dagger p<0.01$. 

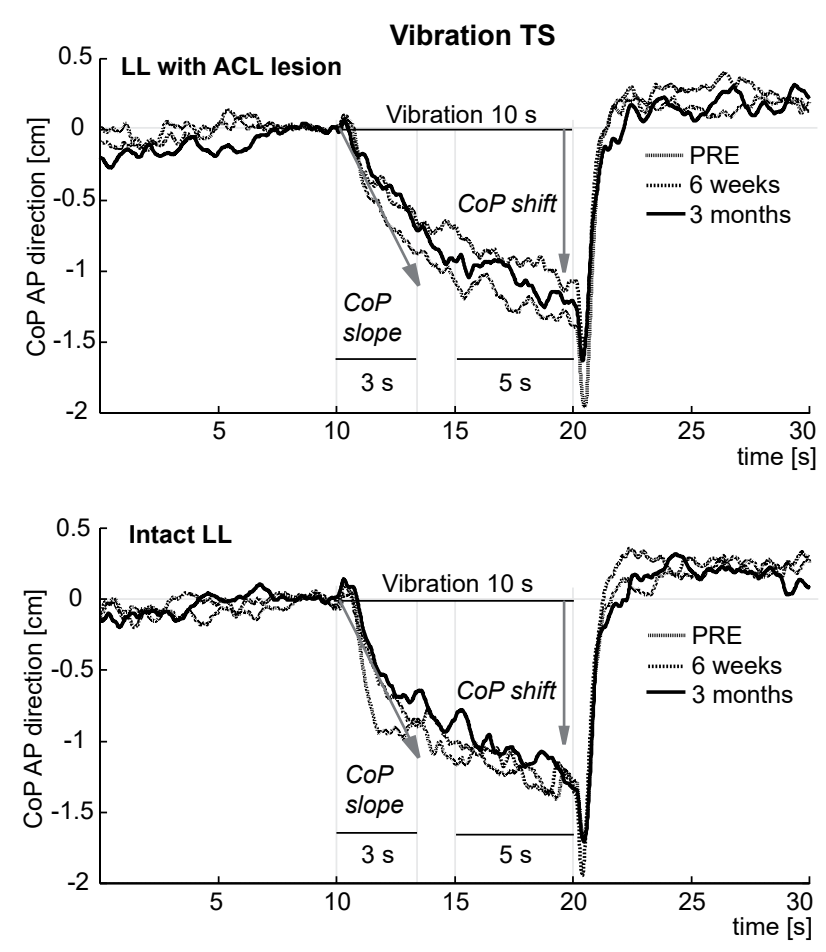

Fig. 3. The mean curves of CoP in AP direction with the parameters: COP slope and COP shift induced by TS vibration before $A C L$ reconstruction (PRE), 6 weeks and 3 months after $\mathrm{ACL}$ reconstruction. Evaluated interval for the CoP slope was: first $3 \mathrm{~s}$ of the TS vibration. Evaluated interval for the CoP shift was: last $5 \mathrm{~s}$ of TS vibration.
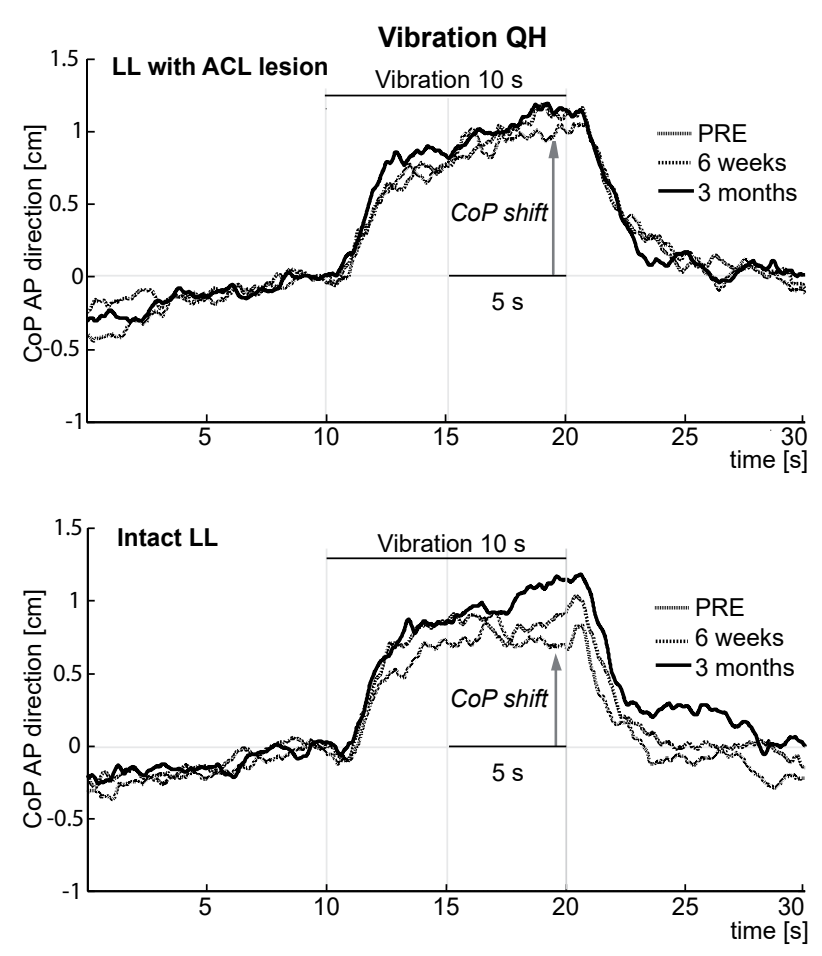

Fig. 4. The mean curves of COP in AP direction with the parameter COP shift induced by $\mathrm{QH}$ vibration before $\mathrm{ACL}$ reconstruction (PRE), 6 weeks and 3 months after $A C L$ reconstruction. Last $5 \mathrm{~s}$ of $\mathrm{QH}$ vibration were evaluated.
Different responses of lower limbs to $\mathrm{QH}$ vibration were observed before the surgical reconstruction. ANOVA showed significant effect of the factor ACL lesion in the CoP shift $(\mathrm{F}=4.189, \mathrm{df}=1$, $\mathrm{p}=0.049$ ). Greater CoP shift was documented during $\mathrm{QH}$ vibration of the LL with the ACL lesion compared to the vibration of intact LL $(\mathrm{p}=0.049)$ proved by post-hoc $t$-test (Table 1, Fig. 4). Preoperatively, we did not find different responses of lower limbs to $\mathrm{Q}$ vibration. Any other differences neither between reactions of lower limbs nor between sessions were found during $\mathrm{Q}$ and $\mathrm{QH}$ vibrations after the ACL reconstruction.

\section{Discussion}

We showed that postural stability in patients with ACL lesion worsened six weeks after the ACL reconstruction with a tendency to return to preoperative level three months after the reconstruction. This was documented by posturography in four static conditions. Vibration of $m$. triceps surae of lower limb with ACL lesion induced altered postural reactions due to impaired proprioception associated with the ACL surgical reconstruction.

Posturographic measurement showed increased sway velocity in AP direction (Vap) during stance on firm surface with eyes open and closed; increased postural sway amplitude in ML direction (Aml) and increased values of LI parameter in EO condition six weeks after the ACL reconstruction. Increase of these parameters indicates higher $\mathrm{CoP}$ oscillations, therein decreased postural stability. Postural instability after ACL reconstruction was documented also in previous studies (Kubisz et al. 2011, Ahmed et al. 2011, Herrington and Fowler 2006, Shiraishi et al. 1996). Three months after the surgical reconstruction, significant improvement of postural stability was observed in the most challenging postural condition: stance on foam surface with eyes closed. Amplitude and velocity of $\mathrm{CoP}$ in $\mathrm{ML}$ direction and also parameter LI significantly decreased compared to the session six weeks after the surgery. Other studies described worsened postural stability after three weeks (Kellis et al. 2011) and even one year (Bonfim et al. 2003) after ACL reconstruction. Though, those patients were tested only during stance on firm surface. In our protocol, posturographic measurement was enlarged with conditions including unstable foam surface with eyes open and closed. The most challenging condition with reduced visual and altered proprioceptive feedback (FEC) 
seems to be very important for monitoring of postural improvement after ACL reconstruction. This improvement of postural stability was at least partly due to focused rehabilitation and intensive training involving exercises on various types of unstable support surfaces. This type of training is aiming to improve proprioception and also anticipatory component of postural control, which are manifested by decreased amplitudes of postural sway (Shumway-Cook and Woollacott 2012). Postural improvement in condition FEC indicates also the improvement of vestibular function, which is dominant during conditions on unstable support surfaces (Horak and Macpherson 1996). Despite the argument of AshtonMiller et al. (2001) that efficacy of current exercises aimed at improving proprioception was not sufficiently proved, the rehabilitation focused on somatosensory function most likely helped to improve sensory integration, postural stabilization and function of injured knee joint.

Our presumption that vibration of $m$. triceps surae of LL with ACL lesion will induce significantly different reactions was proved. Speed of the reaction, represented by the CoP slope, showed slower reaction in response to the TS vibration of LL with ACL lesion compared to the vibration of intact LL in preoperative session. This finding confirms the assumption of proprioceptive deficit in LL with ACL lesion due to damaged afferent part of reflexive arc. Worsened postural orientation during TS vibration of LL with ACL lesion was documented by decreased CoP shift six weeks and also three months after the reconstruction compared to preoperative session. Less adapted responses to $m$. triceps surae vibration may be explained by altered responsiveness of spindles in this muscle (Shanahan et al. 2014). The ACL reconstruction might influence the muscle spindle sensitivity reducing the response to Achilles tendon vibration and cause higher rigidity of injured LL. Persisting proprioceptive deficit after surgical reconstruction was previously documented. The tendency to return to preoperative level was reported after six months (Angoules et al. 2011, Reider et al. 2003), 12 months (Angoules et al. 2011) or 19 months (Gholam et al. 2013). Reaction latency to destabilizing stimulus was found in dynamic posturography even 36 months after the ACL reconstruction (Henriksson et al. 2001). We can presume that period of three months after reconstruction is not long enough for complete restoration process of operated knee joint function and proprioception normalization.
We hypothesized that vibration of knee joint muscles $(\mathrm{Q}, \mathrm{QH})$ of LL with ACL lesion will induce different reactions compared to the vibration of intact LL. Although ACL lesion modified postural symmetry and postural reactions to muscle vibrations, our results are not definite. Preoperatively, we observed higher CoP shift during QH vibration of LL with ACL lesion compared to the vibration of intact LL. Increased CoP shift indicates higher instability of injured knee joint. However, lateral differences in reaction to $\mathrm{QH}$ vibration were not observed after ACL reconstruction. Vibration of $\mathrm{m}$. quadriceps femoris did not induce significantly different reactions. This finding is in agreement with previous study of Ivanenko et al. (2000). It was proved that vibration effect depends on chosen muscle (its function in postural control hierarchy), sensory context and its actual role and functional context. Probable reason of less pronounced differences in reactions to knee joint muscles vibrations $(\mathrm{Q}, \mathrm{QH})$ might be the functional context in which the muscles were examined. Knee joint stabilizators (m. quadriceps femoris, hamstrings) might have more important role in dynamic conditions, e.g. walking (Ivanenko et al. 2000). Also Shanahan et al. (2014) did not observe different $\mathrm{CoP}$ displacement in response to vibration of quadriceps muscle in patients with knee osteoarthritis compared to healthy subjects. Surprisingly they found changes in response to vibration of the plantar flexor muscles ( $m$. triceps surae). They explained these findings by the limited contribution of somatosensory information from the knee and quadriceps muscle to balance control in quiet stance. In quiet standing, the role of knee joint muscles and proprioceptive information from this area is not as important as the role of ankle joint muscles. In quiet standing, the ankle joint strategy (Horak 2006) has the dominant role. Another possible reason for less definite results from knee joint muscles vibrations (Q, QH) might be vibration frequency of $60 \mathrm{~Hz}$. Previous studies proved that velocity and amplitude of postural reactions are directly proportional to used vibration frequency (Abrahámová et al. 2009, Čapičíková et al. 2006). Vibrations with higher frequency would probably evoke more pronounced reactions. Accompanying surgical treatment of meniscus in eight patients might also modify the proprioceptive deficit after the reconstruction and thus influence the results. The coincidence of ACL and meniscus lesion is high (30-40\%), thus we did not exclude these patients from the study. Also vision (eyes open) could play an important role in reweighting of sensory information 
causing less manifested changes in responses to vibrations. The question of reference leg should be also taken into account. The postural system may adopt a voluntary or possibly reactive strategy, involving the transfer of body weight to the non-vibrated limb in order to avoid the perturbing effect of the vibrations. Nevertheless, proprioceptive input from the nonperturbed leg does not completely prevent the anteriorposterior displacement induced by vibration (Duclos et al. 2014), but still might misrepresent the final effect of the vibration.

According to the results we can conclude that postural stability of patients with ACL lesion worsened 6 weeks after ACL surgical reconstruction. Three months after the reconstruction and focused rehabilitation, the improvement of postural stability was observed during the stance on unstable (foam) support surface with eyes closed. Vibration of ankle joint muscle ( $m$. triceps surae) of LL with ACL lesion induced altered postural reactions preoperatively and also after the ACL reconstruction due to impaired proprioception. Posturographic measurements in static conditions and with the vibrations of $m$. triceps surae can reliably detect postural instability and the ability of the patient to compensate the disturbing vibratory inputs to ankle joint muscles. These measurements can be potentially useful in clinical practice in patients after ACL reconstruction.

\section{Conflict of Interest}

There is no conflict of interest.

\section{Acknowledgements}

The work was supported by VEGA grants No. 2/0094/16 and $1 / 0373 / 14$.

\section{References}

ABRAHÁMOVÁ D, HLAVAČKA F: Age-related changes of human balance during quiet stance. Physiol Res 57: 957964, 2008.

ABRAHÁMOVÁ D, MANCINI M, HLAVAČKA F, CHIARI L: The age-related changes of trunk responses to Achilles tendon vibration. Neurosci Lett 467: 220-224, 2009.

AHMED M, MOSALEM D, KHAIRET S, ISMAIL T, HAMIDO F, AL-BUSAIRI W: Evaluation of dynamic posturography in anterior cruciate ligament injury patients. Maced J Med Sci 4: 167-173, 2011.

ANGOULES AG, MAVROGENIS AF, DIMITRIOU R, KARZIS K, DRAKOULAKIS E, MICHOS J, PAPAGELOPOULOS PJ: Knee proprioception following ACL reconstruction: a prospective trial comparing hamstrings with bone-patellar tendon-bone autograft. Knee 18: 76-82, 2011.

ARDERN CL, TAYLOR NF, FELLER JA, WEBSTER KE: Fifty-five per cent return to competitive sport following anterior cruciate ligament reconstruction surgery. Br J Sports Med 48: 1543-1552, 2014.

ASHTON-MILLER JA, WOJTYS EM, HUSTON LJ, FRY-WELCH D: Can proprioception really be improved by exercises? Knee Surg Sports Traumatol Arthrosc 9: 128-136, 2001.

BONFIM TR, JANSEN PACCOLA CA, BARELA JA: Proprioceptive and behavior impairments in individuals with anterior cruciate ligament reconstructed knees. Arch Phys Med Rehabil 84: 1217-1223, 2003.

BRUNETTI O, FILIPPI GM, LORENZINI M, LITI A, PANICHI R, ROSCINI M, PETTOROSSI VE, CERULLI G: Improvement of posture stability by vibratory stimulation following anterior cruciate ligament reconstruction. Knee Surg Sports Traumatol Arthrosc 14: 1180-1187, 2006.

ČAPIČÍKOVÁ N, ROCCHI L, HLAVAČKA F, CHIARI L, CAPPELLO A: Human postural response to lower leg muscle vibration of different duration. Physiol Res 55: 129-134, 2006.

DUCLOS NC, MAYNARD L, BARTHELEMY J, MESURE S: Postural stabilization during bilateral and unilateral vibration of ankle muscles in the sagittal and frontal planes. J Neuroeng Rehabil 11: 130, 2014.

EKLUND G: Further studies of vibration-induced effects on balance. J Med Sci 78: 65-72, 1973.

GHOLAM AG, VAHID Z, KHOSRAVI I, MINASIAN V: Evaluation of joint position sense after ACL reconstruction with hamstring tendon auto graft. Am J Sports Med 1: 52-55, 2013.

HENRIKSSON M, LEDIN T, GOOD L: Postural control after anterior cruciate ligament reconstruction and functional rehabilitation. Am J Sports Med 29: 359-366, 2001.

HERRINGTON L, FOWLER E: A systematic literature review to investigate if we identify those patients who can cope with anterior cruciate ligament deficiency. Knee 13: 260-265, 2006. 
HORAK F: Postural orientation and equilibrium. What do we need to know about neural control of balance to prevent falls? Age Ageing 35 (Suppl 2): 7-11, 2006.

HORAK F, MACPHERSON JM: Postural orientation and equilibrium. In: Handbook of Physiology: Exercise Regulation and Integration of Multiple Systems. ROWELL LB, SHEPARD JT (eds), Oxford University Press, New York, 1996, pp 255-292.

IVANENKO Y P, GRASSO R, LACQUANITI F: Influence of leg muscle vibration on human walking. J Neurophysiol 84: 1737-1747, 2000.

KAPRELI E, ATHANASOPOULOS S: The anterior cruciate ligament deficiency as a model of brain plasticity. Med Hypothes 67: 645-650, 2006.

KAPRELI E, ATHANASOPOULOS S: Anterior cruciate ligament deficiency causes brain plasticity: a functional MRI study. Am J Sports Med 37: 2419-2426, 2009.

KELLIS E, AMIRIDIS IG, KOFOTOLIS N: On the evaluation of postural stability after ACL reconstruction. $J$ Sports Sci Med 10: 422-423, 2011.

KOLÁ̌̌ P: Rehabilitation in Clinical Practice (in Czech). Galén, Prague, 2009.

KUBISZ L, WERNERA H, BOSEK M, WEISS W: Posture stability evaluation using static posturography in patients after cruciate ligament reconstruction. Acta Phys Pol A 119: 957-960, 2011.

KVIST J: Sagittal plane knee motion in the ACL-deficient knee during body weight shift exercises on different support surfaces. J Orthop Sports Phys Ther 36: 954-961, 2006.

KVIST J: Sagittal plane translation during level walking in poor-functioning and well-functioning patients with anterior ligament deficiency. Am J Sports Med 36: 398-407, 2008.

LOBOTKOVÁ J, HALICKÁ Z, BUČKOVÁ K, KILLINGER Z, PAYER Z, HLAVAČKA F: Balance control, vitamin $\mathrm{D}$ and bone resorption marker in elderly women with osteopenia and osteoporosis. Act Nerv Super Rediviva $\mathbf{5 5}$ : 103-112, 2013.

REIDER B, ARCAND MA, DIEHL LH: Proprioception of the knee before and after anterior cruciate ligament reconstruction. Arthroscopy 9: 2-12, 2003.

SHANAHAN CJ, WRIGLEY TV, FARRELL MJ, BENNELL KL, HODGES PW: Postural response to vibration of triceps surae, but not quadriceps muscles, differs between people with and without knee osteoarthritis. J Orthop Res 32: 989-996, 2014.

SHIRAISHI M, MIZUTA H, KUBOTA K, OTSUKA Y, NAGAMOTO N, TAKAGI K: Stabilometric assessment in the anterior cruciate ligament reconstructed knee. Clin J Sport Med 6: 32-39, 1996.

SHUMWAY-COOK A, WOOLLACOTT MH: Motor Control: Translating Research into Clinical Practice. Lippincott, Williams and Wilkins, Baltimore, 2012.

SMILEY-OYEN AL, LOWRY KA, KERR JP: Planning and control of sequential rapid aiming in adults with Parkinson's disease. J Motor Behav 39: 103-114, 2007.

WIKSTROM E, TILLMAN M, CHMIELEWSKI T, BORSA P: Measurement and evaluation of dynamic joint stability of the knee and ankle after injury. Sports Med 36: 393-410, 2006. 